\title{
Reducing financial barriers through the implementation of voucher incentives to promote children's participation in community sport in Australia
}

\author{
L. J. Reece ${ }^{1,2^{*}}$, C. Mclnerney ${ }^{3}$, K. Blazek ${ }^{3}$, B. C. Foley ${ }^{1,2}$, L. Schmutz ${ }^{4}$, B. Bellew ${ }^{1,2}$ and A. E. Bauman ${ }^{1,2}$
}

\begin{abstract}
Background: Participation in organised sport and physical activity contributes to health-enhancing levels of leisure time physical activity. In Australia, 58\% of children aged 0-14 years participated at least once a week in October 2015 - December 2017. To overcome the frequently cited cost barrier, sports voucher incentives have been widely implemented across Australia.

Method: The financial value of jurisdictional vouchers and the National median financial value were used to calculate the proportion of total annual expenditure on children's participation in sport supported by sports vouchers. Participation rates using AusPlay data were estimated by age, sex and socio-economic index (SEIFA) at state and national level for children aged 0-14 years.

Results: Five States and Territories implemented sports vouchers from 2011 to 2018, with a median value of AU\$150. Nationally, median annual expenditure for children's sport participation was AU\$447 (IQR \$194.2-936), with $27 \%$ reported expenditure supported by a sports voucher. The proportion of financial support from sports vouchers increased considerably with social disadvantage, rising to over $60 \%$ of total expenditure in the most disadvantaged populations.

Conclusions: Socio-economic status was associated with sports-related expenditure and sports participation amongst children. Sport vouchers should target children in the most disadvantaged areas to promote participation in organised sport and physical activity.
\end{abstract}

Keywords: Participation, Children and young people, Sport, Physical activity, Voucher program

\section{Background}

Regular participation in physical activity has positive physical, emotional, social and mental health benefits [1] in children and adolescents [2]. To accrue benefits, global children's physical activity guidelines recommend participation in at least $60 \mathrm{~min}$ of moderate intensity physical activity every day [3]. Whilst measurement of

\footnotetext{
* Correspondence: lindsey.reece@sydney.edu.au

'SPRINTER (The Prevention Research Collaboration's Sport and Active Recreation Intervention \& Epidemiology Research Group), Prevention Research Collaboration, School of Public Health, University of Sydney, D17 Charles Perkins Centre, Level 6, the Hub, Camperdown, NSW 2006, Australia ${ }^{2}$ Charles Perkins Centre, The University of Sydney, Camperdown, NSW, Australia

Full list of author information is available at the end of the article
}

global child participation in physical activity remains complex [4] the global prevalence of adolescent physical inactivity is estimated at $80.3 \%(95 \% \mathrm{CI} 80.1-80.5)$ with girls less active than boys [4]. Data from an Australian school based population survey of school with children aged 5 to 16 years data reinforces this, with only 1 in 5 children and adolescents (19\%) meeting the daily physical activity recommendations [5]. Girls (15\%) were less likely to meet the recommendation than boys (24\%) along with children from urban areas (18\%) and those from Middle Eastern (13\%) and Asian cultural backgrounds (9\%). Participation is frequently lower for children living in less affluent regions and who have inactive parents [6]. Less is known about the type of physical

(c) The Author(s). 2020 Open Access This article is distributed under the terms of the Creative Commons Attribution 4.0 International License (http://creativecommons.org/licenses/by/4.0/), which permits unrestricted use, distribution, and reproduction in any medium, provided you give appropriate credit to the original author(s) and the source, provide a link to the Creative Commons license, and indicate if changes were made. The Creative Commons Public Domain Dedication waiver (http://creativecommons.org/publicdomain/zero/1.0/) applies to the data made available in this article, unless otherwise stated. 
activities children participate in during leisure time [7] considering that active participation can occur in different physical activity domains, including sport.

Sport which is typically organised and structured, and played individually or within a team $[1,8]$ has been reported to produce various psychological and social health benefits that exceeds other forms of leisure time activity for children and adolescents $[1,8]$. Sports club participation in Australia has been found to contribute significantly to leisure time activity [9] with clubs acting as the main avenue for both girls and boys under 15 years old to be active outside of the school environment. Despite the potential benefits, only $20 \%$ of children participate in organised sport outside of school hours at least three times per week [10]. Gender differences in participation are clear with boys most likely to continue to participate in sport throughout childhood whilst girls often see the competitive element of sports as a barrier to participation [11].

The main barriers to participating in physical activity and structured sport amongst children and young people include cost, accessibility, lack of parental support and a lack of local facilities $[12,13]$. Associated with lower participation rates, families from the most disadvantaged areas are more substantially affected by these barriers. For example, families with low socio-economic status experience prohibitive costs associated with sporting registration, opportunities and equipment $[14,15]$.

Interventions to overcome cost barriers have been proposed with financial incentives and voucher programs receiving attention in adults. A systematic review of effectiveness of financial incentives used for promoting physical activity in the healthcare setting amongst adults found limited evidence and was inconclusive regarding their effectiveness on physical activity in this setting [16]. Lack of effectiveness was also the theme in research into the uptake and effectiveness of the Children's Fitness Tax Credit in Canada (CFTC) [17]. Parents in the lowest income quartile were significantly less aware of and less likely to claim the CFTC than other income groups [17].Among parents who had claimed the CFTC, few (15.6\%) believed it had increased their child's participation in physical activity programs. It was concluded that whilst more than half of Canadian parents with children had claimed the CFTC, the tax credit scheme appeared to benefit wealthier families [17]. By contrast, a secondary school based voucher program in Wales, United Kingdom (UK), examined the effect of a multicomponent voucher based intervention on the cardiovascular fitness and physical activity levels of teenagers aged 13-14 years in seven schools in Swansea (4 intervention and 3 control schools) called ACTIVE. This scheme positively influenced attitudes to physical activity and enabled children from disadvantaged backgrounds to access broader opportunities to participate in sport and physical activity [15].

With the inconclusive evidence on best practice strategies and the potential to achieve a $25 \%$ relative increase in population physical activity [18] the use of sports vouchers has been widely implemented across Australia. The aim of this paper is to examine Australian's annual expenditure on children's sport and assess the financial support achieved through sport vouchers across different states and territories, as a means of overcoming financial barriers and increasing Australian children's participation in organised sport.

\section{Method}

Data from AusPlay, the Australian sport sector's national population participation assessment, were provided by the Australian Sports Commission [10]. The Computer Assisted Telephone Interviews (CATI) use overlapping dual frames of landline or mobile phones with 13 strata based on states, territories and greater capital city areas for continuous tracking all year long. Data reported here spanned the time period from October 2015 to December 2017 and included 7976 children with information on sport participation. Information on children was obtained from the child's parent or guardian. Weights (Hughes et al., 2017) were calculated per quarter and adjusted for the number of quarters used in the analysis. A proxy measure for socio-economic status (SES) was calculated using the Australian Bureau of Statistics' (ABS) Index of Relative Socio-economic Disadvantage (IRSD, 2016). The national percentiles of SES were used and were grouped into quartiles, with the first quartile corresponding to the most disadvantaged. Participation rates were estimated for Australia and by states/territories according to sex, age group or SEIFA quartile. Using the Sport sector definition in AusPlay, a participant was defined as someone who has participated in at least 1 session of organised sport in the preceding 12 months with sport related costs defined as money paid to the organisation or venue [18]. All analyses incorporated the complex survey design and were mainly done using SAS software (version 9.4, Copyright $\odot 2016$ by SAS Institute Inc., Cary, NC, USA) using SAS/STAT survey analysis procedures. For design based Mood's test of medians, $\mathrm{R}$ 3.4.0 [19] and the survey package [20] were used.

A review of voucher schemes across Australian states and territories (Bellew and Young, 2017) provided detail on existence, delivery dates and voucher value. In brief here, The Sport Voucher scheme in Northern Territory, led by Northern Territory government and administered by the Department of Tourism Sport and Culture [21], provides children in urban areas to claim a $\$ 100$ voucher twice a year and activities for remote children are coordinated by Regional Councils. At the time of publication, 
Victoria does not have a sport voucher scheme and Australian Capital Territory offered grants and other initiatives for being active [22]. KidSport in Western Australia enables children aged 5-18 years to participation in community sport and recreation [23]; FairPlay vouchers in Queensland focuses on children aged 5 to 17 years old [24] and Ticket to play in Tasmania is a governed funded program giving $\$ 100$ to children aged 5-17 [25]. All schemes provide assistance with membership and registration fees.

The total annual cost of participation for children in each State/Territory were estimated. The value of vouchers for individual States and Territories and the national median were used to calculate the proportion of total annual expenditure supported by sports vouchers [21].

\section{Results}

\section{Implementation of voucher schemes}

Between 2011 and 2018, five out of the eight Australian State and Territory Governments have implemented a sports voucher scheme to children and adolescents aged between 0 and 18 years old. The median voucher value was AU\$150 p.a. (range AU\$50-200 p.a.).

\section{State and national participation rates}

$71 \%$ of Australian children took part in one or more organised sport or physical activity sessions outside of school hours, in the preceding 12 months. State variations exist with Tasmania at $61.2 \%$ ranging to Australian Capital Territory at $73.5 \%$. Nationally, girls (70.6\%) participation is slightly lower than boys (72.0\%) yet this is not consistent across all states and territories, with girls exceeding the participation rates of boys in Tasmania and Victoria by 22 and $2.2 \%$ respectively. When assessing weekly participation in sport, national rates drop to $58.3 \%$ with boys and girls participation equal (see Fig. 1a). There is a continuous linear increase in participation both annually and weekly in areas of increased socio-economic advantaged. The difference nationally between the most and least disadvantaged areas in annual and weekly participation is $17 \%$ where those living in the most disadvantaged regions participated substantially less (see Fig. 1b).

\section{Individual expenditure on one child's sport participation}

Nationally, $94.8 \%$ of parents/carers with active children reported paying for their child's participation in organised sport and physical activity outside of school hours in the last 12 months. Median annual expenditure of all activities was \$447 (IQR \$194.2-936), with girls participation costing more than boys (\$103 difference in medians, $p<0.001$ ) (Table 1). Median expenditure increases with age, from a median spend of \$397 at 0-4 years and peaking at \$479 amongst 9-11 year olds, although the test for medians across age groups was not significant (Table 1).

Socio-economic status influences total annual expenditure on sport with people living in the most disadvantaged communities spending less than half the amount spent by the least disadvantaged communities ( $\$ 311$ difference in medians, $\mathrm{p}<0.001$ ).

\section{Proportion of median annual expenditure supported by state voucher}

An assessment of the proportion of the median annual expenditure in each State met by their local sport voucher subsidy was conducted (Fig. 2). Northern Territory supported $80 \%$ of all costs, Western Australia 42\%, Queensland 37\%, NSW 23\%, and South Australia 11\%
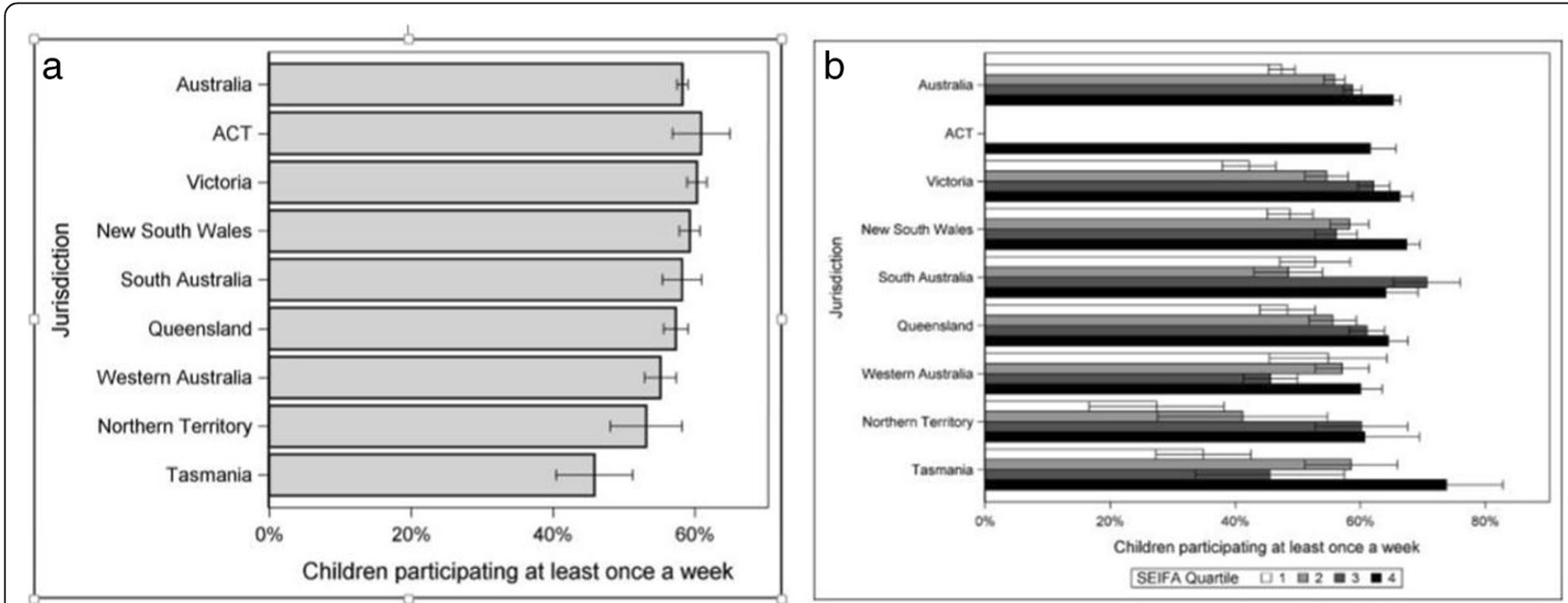

Fig. 1 a Participation rates (at least once a week) by state. Bars represent standard error. b Participation rates (at least once a week) by SEIFA for all of Australia. Bars represent standard error 


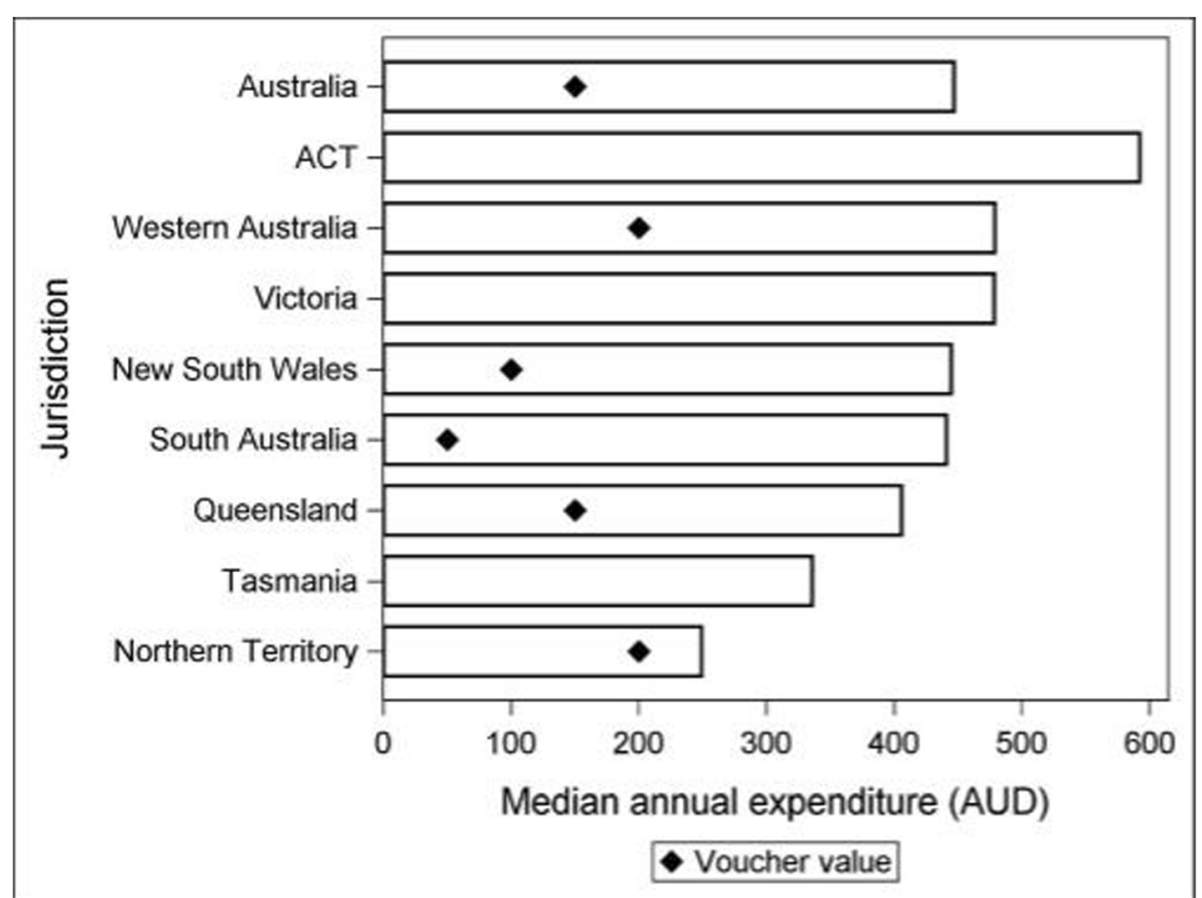

Fig. 2 Median spend per child per year by state with value of state vouchers (where available) indicated with the diamond. The voucher value for Australia is the median value of the state vouchers (AUD150)

respectively. An inverse relationship is observed between expenditure and socio-economic status, with annual expenditure rising with decreasing disadvantage across all states and territories. The implementation of a voucher consistently supports a larger proportion of overall costs for children reporting lower expenditure.

Table 1 Median yearly spend per child by sex, age group and SES. (IQR, interquartile range)

\begin{tabular}{lll}
\hline Category (group-wise $p$-value $\left.{ }^{\mathrm{a}}\right)$ & Median & IQR \\
\hline Sex $(<0.001)$ & 396 & 177,834 \\
$\quad$ Male & 499 & 197,1037 \\
$\quad$ Female & & \\
Age $(0.649)$ & 397 & 124,777 \\
$0-4$ & 445 & 177,992 \\
$5-8$ & 479 & 198,1001 \\
$9-11$ & 449 & 211,900 \\
$12-14$ & & 119,651 \\
SEIFA quartile (<0.001) & 249 & 158,779 \\
1 (most disadvantaged) & 369 & 160,935 \\
2 & 446 & 248,1151 \\
3 & 560 &
\end{tabular}

a Design-based Mood's test for the median
Proportion of children's sport expenditure supported by median Australian sport voucher value

To overcome state-wide variations, applying a median Australian voucher value, $\$ 150$, identified that overall $34 \%$ of child sport related costs are supported, with marginal differences associated with gender and age. Applying the median national voucher value reinforces the bigger contribution to boys' sports related costs (38\%) and children aged 0-4 years (38\%). A dose-response relationship exists between expenditure and SES, with more than half, (60\%) of annual sport-related spend in the most disadvantaged communities supported by the implementation of a $\$ 150$ voucher, compared to $27 \%$ least disadvantaged areas.

\section{Discussion}

In the absence of national endorsement for the implementation of vouchers in Australia, most States and Territories have implemented state wide financial incentive schemes since 2011. Although each jurisdiction has taken a different approach either by voucher value or target audience, the principle consistently focused on the promotion of sport participation. This paper explored the effects of sport voucher programs at state and national level in Australia to reduce financial barriers to children's sport participation. This analysis enhances existing evidence on family expenditure for sport [12] 
Existing evidence infers the positive effect of financial incentives to increase physical activity amongst adults $[16,26]$. Whilst frequently adopted in Australia, global comparisons are challenging, as their use is sparse with only selected countries including the United Kingdom, Luxembourg and Czech Republic, utilising this approach $[15,27,28]$.Whilst the assessment of voucher program efficacy was not the purpose of this paper this was the first robust analysis to assess the proportion of individual sport-related expenditure supported by a voucher and its potential association with child participation rates, using the national population surveillance tool AusPlay, collectively analysed by age, sex and socioeconomic status.

Nearly all parents of active children reported making annual payments for their child's participation in organised sport and physical activity outside of school. National median expenditure for children aged 0-14 years was $\$ 447$ (IQR 194.2-936), peaking in the 9-11 age category (\$479; IQR 198.3-1001.2). Girls expenditure was consistently higher than boys (\$499; IQR 197.4-1036.7) most likely, in light of girls preferred activities, such as dance which are frequently performed in specialised venues [10].

A previous narrative review [21] of voucher schemes explored their role in influencing participation and identified that within a multi-component strategy there was potential for a $25 \%$ relative increase in participation [26]. This, coupled with the expenditure data analysed here begins to describe the potential that a voucher scheme could contribute towards children's physical activity levels.

The social inequalities in sport and physical activity amongst children and adolescents $[8,29]$ are reinforced through these analyses. Children in areas of low socioeconomic status participated less frequently in organised sports and physical activity outside of school hours than their advantaged counterparts. A higher sporting club membership exists amongst higher income families $[2,8$, 30 ] with children from advantaged communities more likely to receive greater logistical and financial support from the families to participate in consistent structured activity [31]. Disparities in the presence, geographic accessibility and affordability of sporting and recreational facilities have also been shown to influence child participation $[8,9]$. Differences in the inclination towards sport can also be explained by economic factors as the traditional club based membership structures require financial outlay beyond sports club membership, including sports equipment and potential transportation costs [12, 29]. The dose response relationship between expenditure and socio-economic status was an important finding in this analysis, with a \$311 difference in median expenditure between the most disadvantaged and least disadvantaged. The potential benefits of sport vouchers shows a social gradient, with $60 \%$ of current reported costs supported in the most disadvantaged areas. This is one step towards alleviating the financial barrier for disadvantaged communities to engage in sport. This finding is also reinforced at a State level, when applying individual state voucher values. For example NSW, the latest state to implement a voucher program, $36 \%$ sport related costs are supported by the $\$ 100$ voucher in the most disadvantaged areas compared to only $19 \%$ in the least disadvantaged communities. As a result, it is important that whilst the implementation of universal voucher programs at state and national level offer potential to influence population participation, they must consider the specific targeting of priority groups including individuals from disadvantaged communities, children from CALD backgrounds, those in the overweight or obese body mass index categories, and children who are low active or completely inactive, to prevent a widening of the social gradient.

\section{Limitations}

As participation is defined as at least one session of organised sport and physical activity outside of school hours in the last 12 months, it only represents a small fraction of health-related physical activity. Estimates of regular participation during leisure time are needed to learn more about the contribution of sport participation in overall leisure time physical activity. Further, parental report is used for most children's organised sport and physical activity surveillance $[9,12,32]$ and may have decreased reliability among adolescents.

\section{Conclusion}

There is a clear opportunity for state-wide participation strategies, including the implementation of voucher programs, to promote participation in sport through their impact on financial costs of sport participation. Thorough evaluations of such programs are needed in order to understand the mechanisms which could result in larger-scale physical activity behavior change. Whilst understanding of the determinants remain unclear for sport, this paper reinforces the social gradient in child sport participation highlighting that the dose response relationship is also apparent in sport-related expenditure, with increasing expenditure with increasing advantage. It is therefore critical that the implementation of voucher programs focus on equitable and accessible participation by the specific targeting of of priority groups, including inactive and priority population, in order to reduce the gap between the least and most socioeconomically disadvantaged areas. 


\section{Abbreviations}

ABS: Australian Bureau of Statistics; CATI: Computer Assisted Telephone Interviews; CFTC: Children's Fitness Tax Credit in Canada; IRSD: Relative Socioeconomic Disadvantage; SEIFA: Socio-economic Indexes for Areas; SES: Socioeconomic status; UK: United Kingdom

\section{Acknowledgments}

This work was completed while Carol Mclnerney and Katrina Blazek were employed as trainees on the NSW Biostatistics Training Program funded by the NSW Ministry of Health. They undertook this work whilst based at the Prevention Research Collaboration, Charles Perkins Centre at the School of Public Health, The University of Sydney.

\section{Authors' contributions}

$L R$ led the writing of this paper with support from BF, with data access support by LS. CM and KB led the analytical work. BB and $A B$ provided senior guidance throughout the research process with through reviews provided. All authors have read and approved this manuscript.

\section{Funding}

The SPRINTER research group is a research partnership between the University of Sydney and Office of Sport NSW Government and receives funding from the Office of Sport to complete an annual workplan of agreed academic and policy relevant deliverables. It is through this research group that this piece of research was conducted. The Office of Sport however did not have any role in the study design, data collection, analysis or write up of this research.

\section{Availability of data and materials}

The data that support the findings of this study are available from Australian Sports Commission but restrictions apply to the availability of these data, which were used under license for the current study, and so are not publicly available. Data are however available from the authors upon reasonable request and with permission of Australian Sports Commission.

\section{Ethics approval and consent to participate}

This manuscript includes secondary analysis of population surveillance data. A data agreement is in place between the University of Sydney and the Australian Sports Commission which details rights to publish. In true partnership, colleagues of the Australian Sports Commission supported with the analysis and therefore an author on this paper.

\section{Consent for publication}

This manuscript involved secondary analysis of data which was handled in accordance with the data agreement we had in place with Sport Australia.

\section{Competing interests}

All authors have no competing interests.

\section{Author details}

${ }^{1}$ SPRINTER (The Prevention Research Collaboration's Sport and Active Recreation Intervention \& Epidemiology Research Group), Prevention Research Collaboration, School of Public Health, University of Sydney, D17 Charles Perkins Centre, Level 6, the Hub, Camperdown, NSW 2006, Australia. ${ }^{2}$ Charles Perkins Centre, The University of Sydney, Camperdown, NSW, Australia. ${ }^{3}$ Biostatistics Training program NSW Ministry of Health Government, Sydney, Australia. ${ }^{4}$ Australian Sports Commission, Canberra, Australia.

\section{Received: 18 July 2019 Accepted: 8 December 2019}

\section{Published online: 07 January 2020}

\section{References}

1. Eime RM, Young JA, Harvey JT, Charity MJ, Payne WR. A systematic review of the psychological and social benefits of participation in sport for children and adolescents: informing development of a conceptual model of health through sport. Int J Behav Nutr Phys Act. 2013;10:98.

2. Janssen I, LeBlanc AG. Systematic review of the health benefits of physical activity and fitness in school-aged children and youth. Int J Behav Nutr Phys Act. 2010;7(1):40

3. World Health Organisation. Global recommendations on physical activity for health. Geneva: World Health Organisation; 2010.
4. Hallal PC, Andersen LB, Bull FC, Guthold R, Haskell W, Ekelund U. Lancet physical activity series working group. Global physical activity levels: surveillance progress, pitfalls, and prospects. Lancet. 2012;380(9838):247-57.

5. Hardy LL, Mihrshahi S, Drayton BA, Bauman A. NSW schools physical activity and nutrition survey (SPANS) 2015: full report. Sydney: NSW Department of Health; 2016.

6. Zahner L, Muehlbauer T, Schmid M, Meyer U, Puder JJ, Kriemler S. Association of sports club participation with fitness and fatness in children. Med Sci Sports Exerc. 2009;41(2):344-50.

7. Hulteen RM, Smith JJ, Morgan PJ, Barnett LM, Hallal PC, Colyvas K, et al. Global participation in sport and leisure-time physical activities: a systematic review and meta-analysis. Prev Med. 2017;95:14-25.

8. Eime RM, Harvey JT, Craike MJ, Symons CM, Payne WR. Family support and ease of access link socio-economic status and sports club membership in adolescent girls: a mediation study. Int J Behav Nutr Phys Act. 2013:10:50.

9. Eime RM, Sawyer N, Harvey JT, Casey MM, Westerbeek H, Payne WR. Integrating public health and sport management: SPORT participation trends 2001-2010. Sport Manag Rev. 2015;18(2):207-17.

10. Australian Sports Commission. AusPlay participation data for the sport sector: summary of key national findings October 2015 to September 2016 data. Canberra: Australian Government; 2016.

11. Knowles AM, Niven A, Fawkner S. A qualitative examination of factors related to the decrease in physical activity behavior in adolescent girls during the transition from primary to secondary school. J Phys Act Health. 2011;8(8):1084-91.

12. Aitken R, King L, Bauman A. A comparison of Australian families' expenditure on active and screen-based recreation using the ABS Household Expenditure Survey 2003/04. Aust N Z J Public Health. 2008:32(3):238-45.

13. Charlton R, Gravenor MB, Rees A, Knox G, Hill R, Rahman MA, Jones K, Christian D, Baker JS, Stratton G, Brophy S. Factors associated with low fitness in adolescents-a mixed methods study. BMC Public Health. 2014;14(1):764.

14. Hardy LL, Kelly B, Chapman K, King L, Farrell L. Parental perceptions of barriers to children's participation in organised sport in Australia. J Paediatr Child Health. 2010:46(4):197-203.

15. Christian D, Todd C, Hill R, Rance J, Mackintosh K, Stratton G, et al. Active children through incentive vouchers - evaluation (ACTIVE): a mixed-method feasibility study. BMC Public Health. 2016;8:15.

16. Molema CCM, Wendel-Vos GCW, Puijk L, Jensen JD, Schuit AJ, de Wit GA. A systematic review of financial incentives given in the healthcare setting; do they effectively improve physical activity levels? BMC Sports Sci Med Rehabil. 2016;8:15. https://doi.org/10.1186/s13102-016-0041-1.

17. Spence JC, Holt NL, Dutove JK, Carson V. Uptake and effectiveness of the Children's fitness tax credit in Canada: the rich get richer. BMC Public Health. 2010;10(1):356

18. Hughes P. AusPlay: second methodology report; 2017.

19. R Core Team. R: a language and environment for statistical computing. Vienna. URL https://www.R-project.org: R Foundation for Statistical Computing; 2016.

20. Lumley T. Analysis of complex survey samples. J Stat Softw. 2004;9:8. https:// doi.org/10.18637/jss.v009.i08.

21. The Northern Territory sport voucher scheme. https://nt.gov.au/leisure/ sport/sport-and-swim-vouchers/sport-voucher-scheme-urban/get-sportvouchers-for-your-child. Accessed 4 Nov 2019.

22. Office of Sport, ACT government. https://www.sport.act.gov.au/grants. Accessed 4 Nov 2019.

23. Office of Sport, Western Australia government. https://www.wa.gov.au/ service/sport-and-recreation/sport-and-fitness-development/apply-kidsport. Accessed 4 Nov 2019

24. Office of Sport Queensland government. https://qorf.org.au/get-startedvouchers-open-for-2019/. Accessed 4 Nov 2019.

25. Communities Tasmania. https://www.communities.tas.gov.au/ticket-to-play/ apply-for-a-voucher. Accessed 4 Nov 2019

26. Kahn EB, Ramsey LT, Brownson RC, Heath GW, Howze EH, Powell KE, Stone EJ, Rajab MW, Corso P. The effectiveness of interventions to increase physical activity: a systematic review1, 2. Am J Prev Med. 2002;22(4):73-107.

27. Bellew B, Young S. Voucher schemes to promote increased participation in sport and active recreation: rapid evidence review for the NSW Office of Sport. SPRINTER Group. Camperdown: The University of Sydney; 2017.

28. Pavlík M, de Vries MS. Municipal Grants for sports and the merits of a voucher system in the Czech Republic. NISP Acee J Public Adm Policy. 2013; $6(1): 9-30$ 
29. Stalsberg R, Pedersen AV. Effects of socioeconomic status on the physical activity in adolescents: a systematic review of the evidence. Scand I Med Sci Sports. 2010;20(3):368-83.

30. Kantomaa MT, Tammelin TH, Näyhä S, Taanila AM. Adolescents' physical activity in relation to family income and parents' education. Prev Med. 2007; 44(5):410-5.

31. Brockman R, Jago R, Fox KR, Thompson JL, Cartwright K, Page AS. "Get off the sofa and go and play": family and socioeconomic influences on the physical activity of 10-11 year old children. BMC Public Health. 2009;9(1):253.

32. Chau J, Smith BJ, Bauman A, Merom D, Eyeson-Annan M, Chey T, et al. Recent trends in physical activity in New South Wales. Is the tide of inactivity turning? Aust N Z J Public Health. 2008;32(1):82-5.

\section{Publisher's Note}

Springer Nature remains neutral with regard to jurisdictional claims in published maps and institutional affiliations.

Ready to submit your research? Choose BMC and benefit from:

- fast, convenient online submission

- thorough peer review by experienced researchers in your field

- rapid publication on acceptance

- support for research data, including large and complex data types

- gold Open Access which fosters wider collaboration and increased citations

- maximum visibility for your research: over $100 \mathrm{M}$ website views per year

At BMC, research is always in progress.

Learn more biomedcentral.com/submissions 